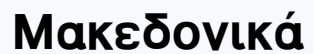

Tóp. 32, Ap. 1 (2000)

MAKGДONIKA

¿YГГРАMMA ПЕPIOAIKON

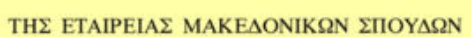

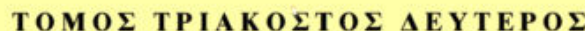

$1999-2000$

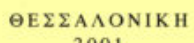

2001

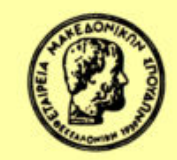

Sharon Gerstel, Beholding the sacred mysteries, programs of the byzantine sanctuary

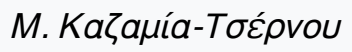

doi: 10.12681/makedonika.186

Copyright $\odot$ 2014, MAKE $\triangle$ ONIKA

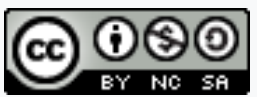

Aঠ¿ıı Xpńбnৎ Creative Commons Attribution-NonCommercial-ShareAlike 4.0.

\section{Bıßлıоррачıкń avaчopá:}

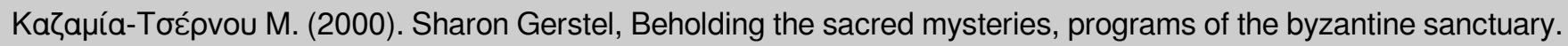
Макєঠоvıка́, 32(1), 534-541. https://doi.org/10.12681/makedonika.186 
Sharon Gerstel, Beholding the sacred mysteries, Programs of the Byzantine Sanctuary, (College Art Association. Monograph on the Fine Arts, LVI. Ed. Debra Pincus), Seattle and

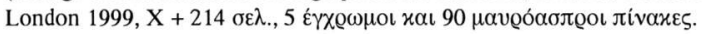

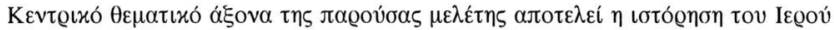

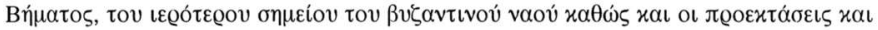

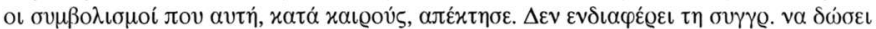

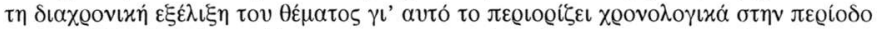

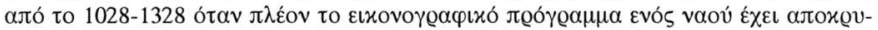

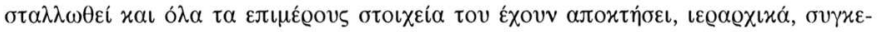

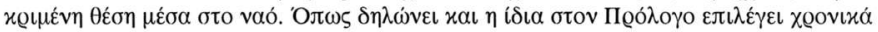

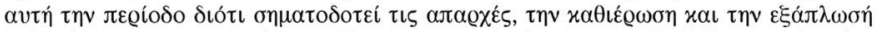

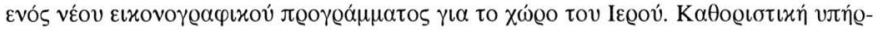

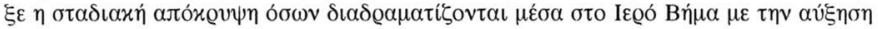

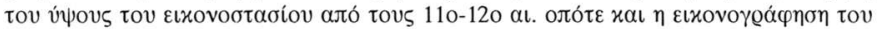

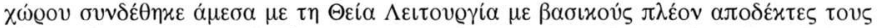

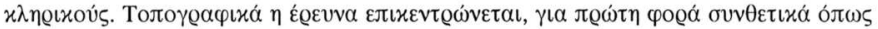

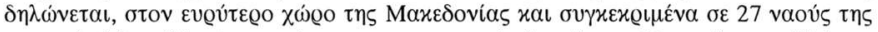

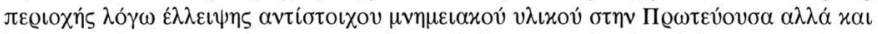

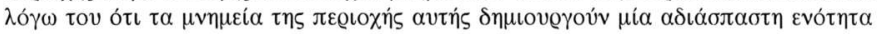

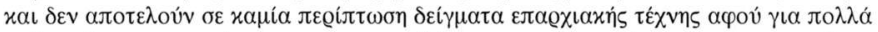

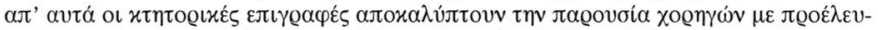

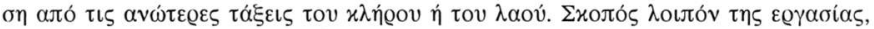

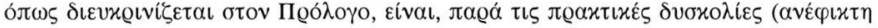

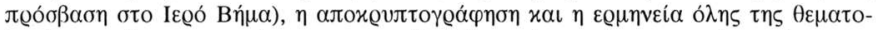

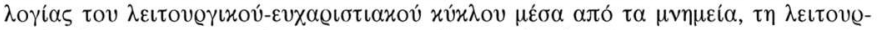

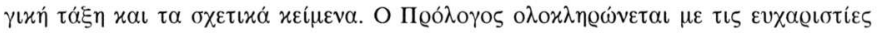

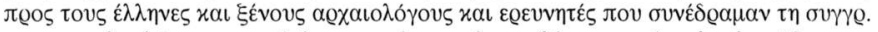

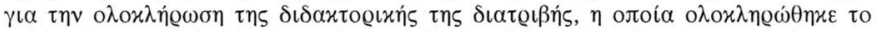

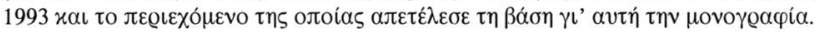

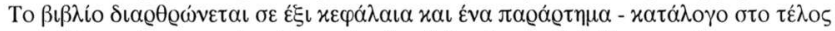

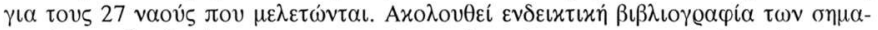

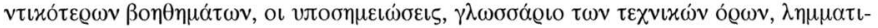

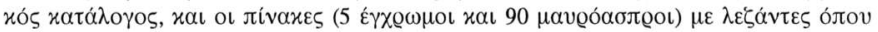

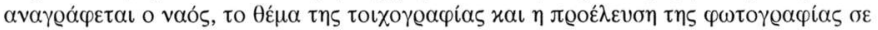

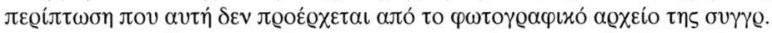

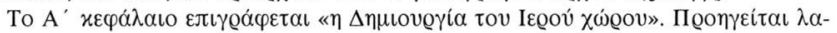

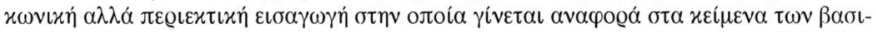

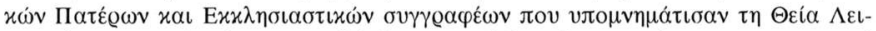

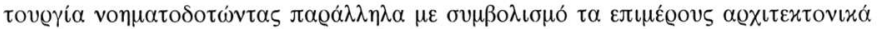

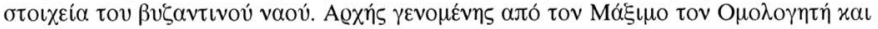

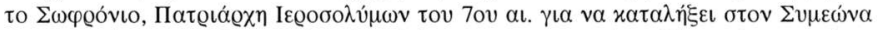

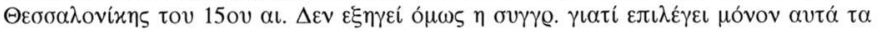

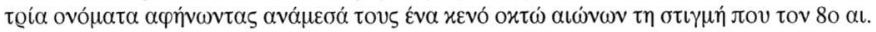

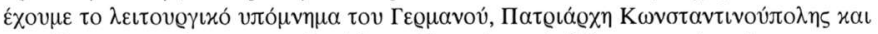

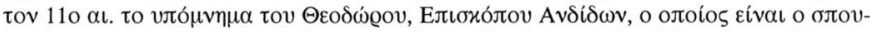

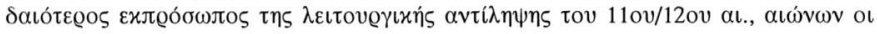


олоі́ь ع

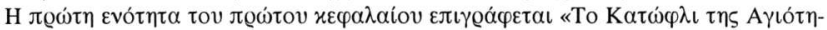

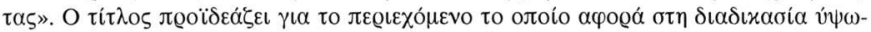

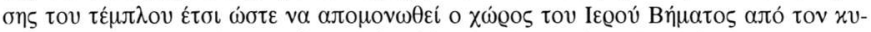

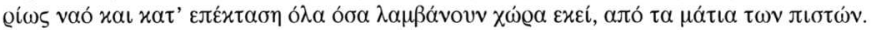

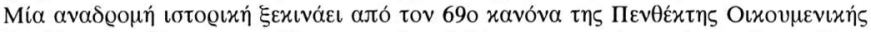

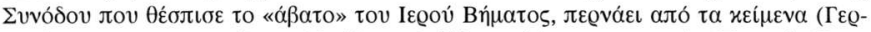

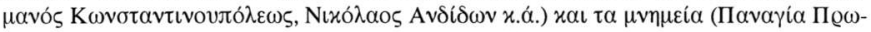

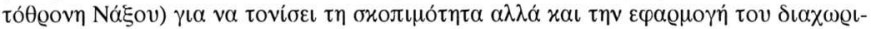

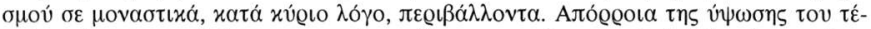

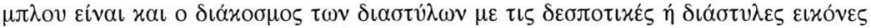

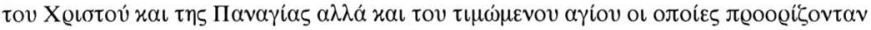

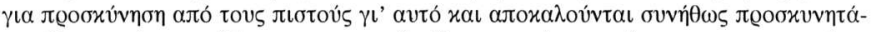

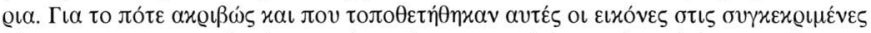

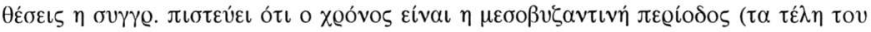

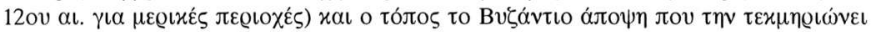

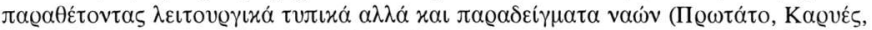

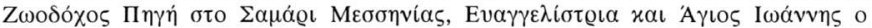

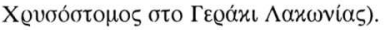

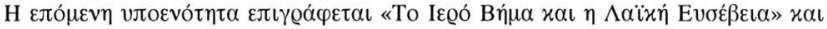

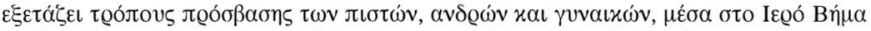

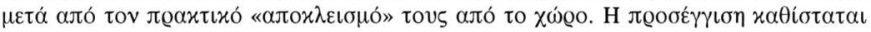

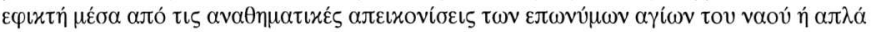

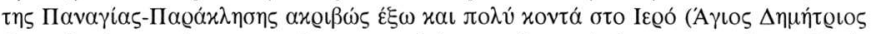

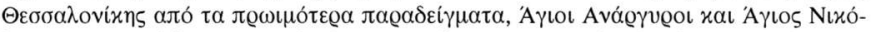

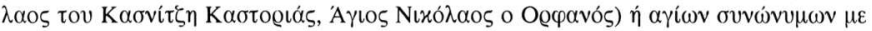

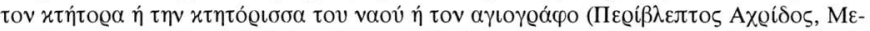

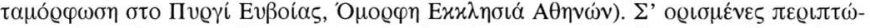

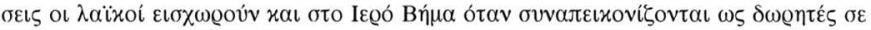

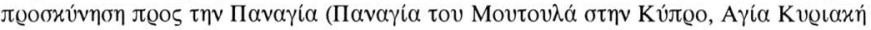

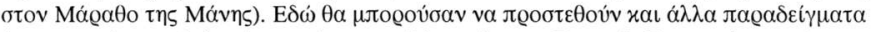

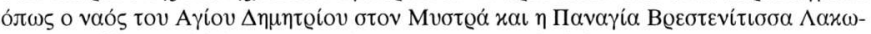

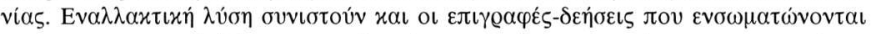

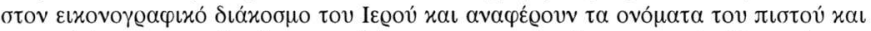

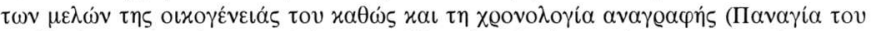

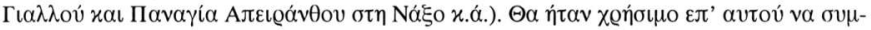

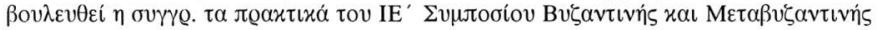

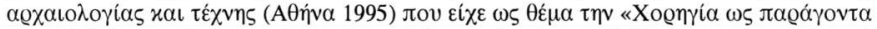

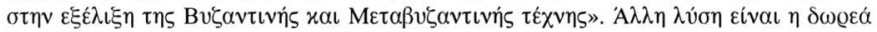

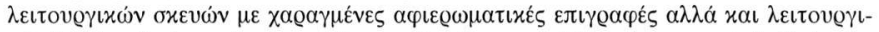

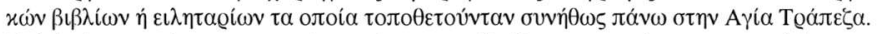

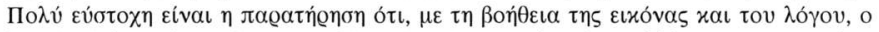

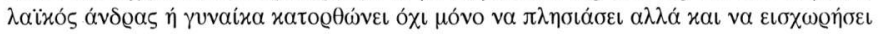

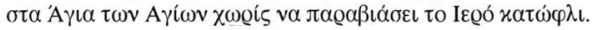

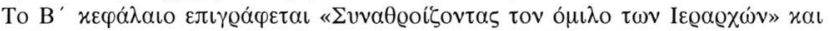

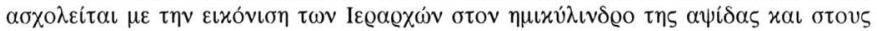

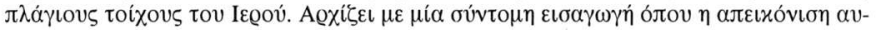




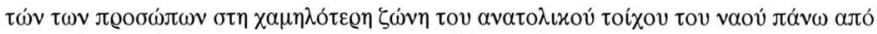

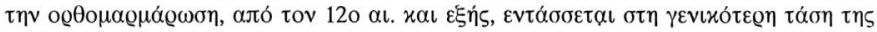

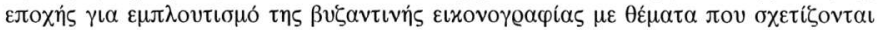

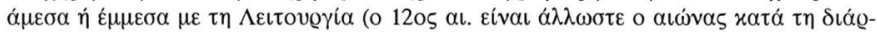

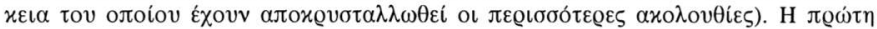

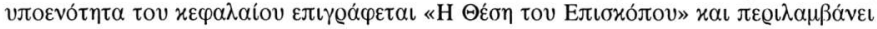

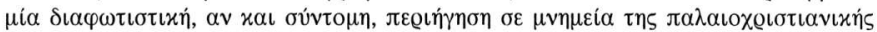
(A

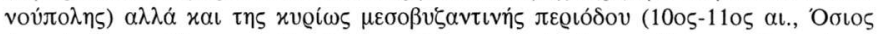

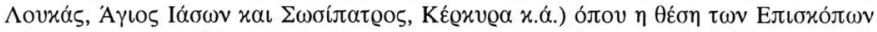

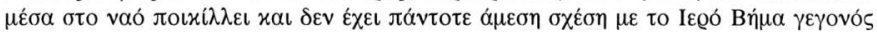

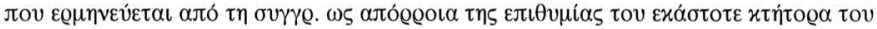

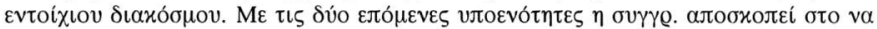

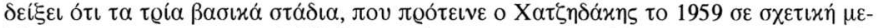

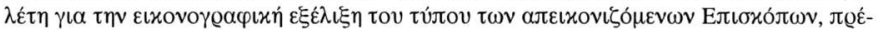

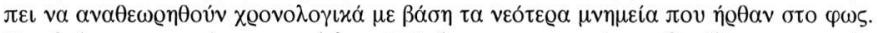

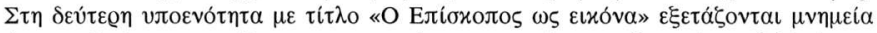

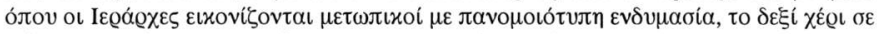

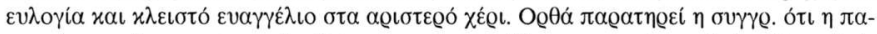

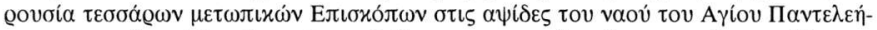

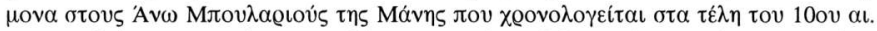

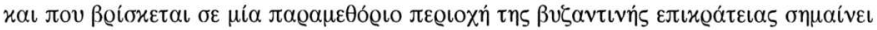

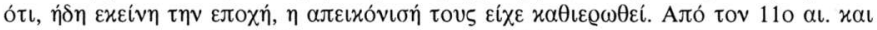

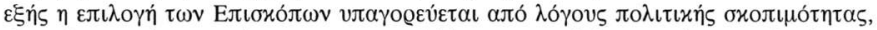

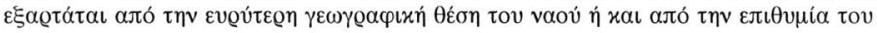

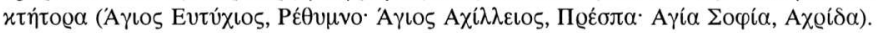

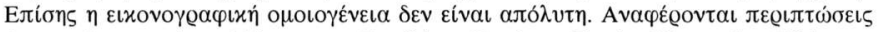

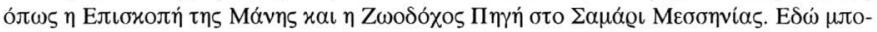

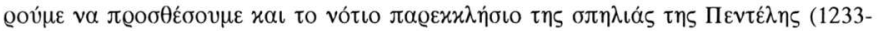

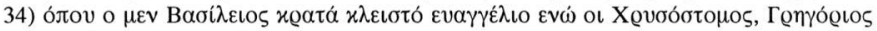

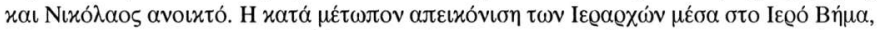

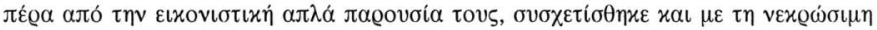

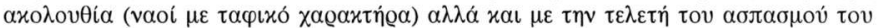

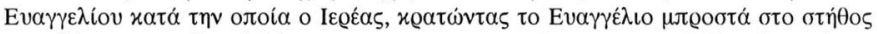

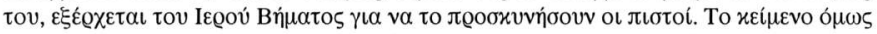

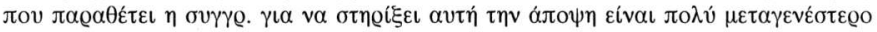

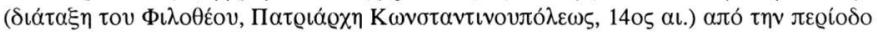

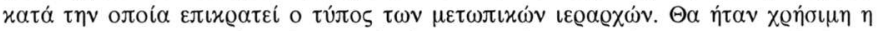

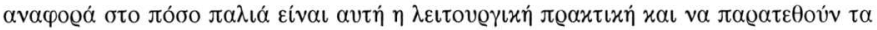

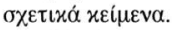

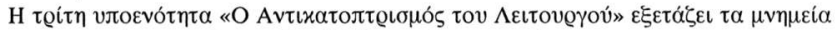

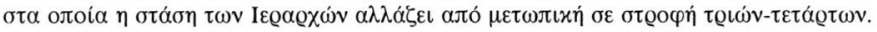

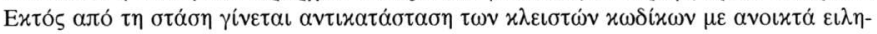

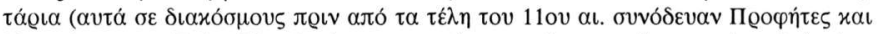

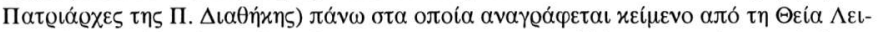

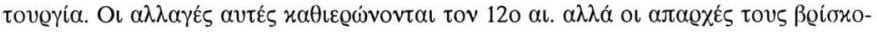

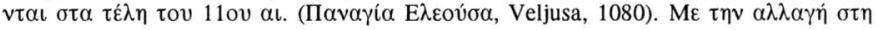




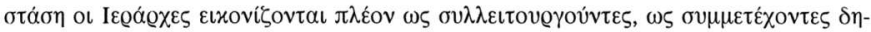

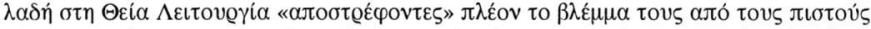

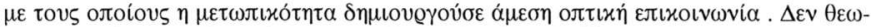

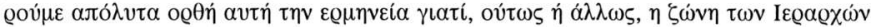

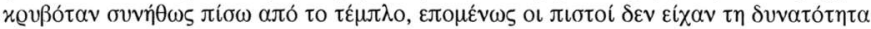

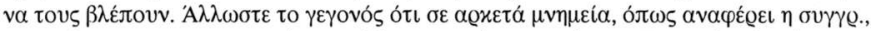

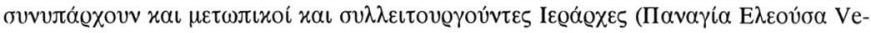

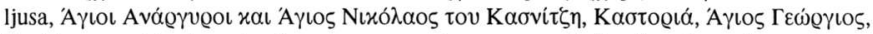

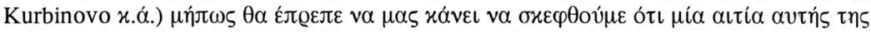

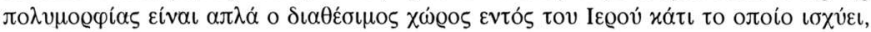

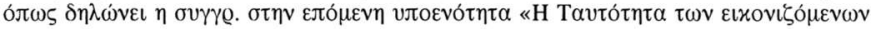

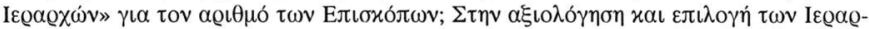

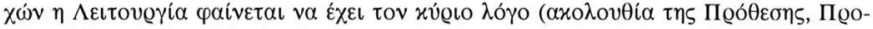

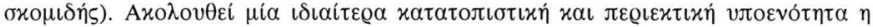

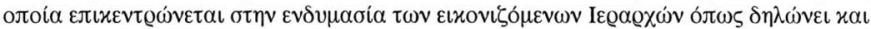

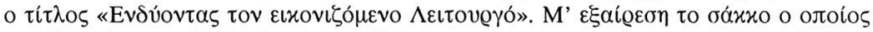

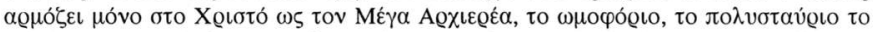

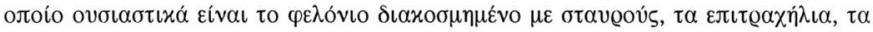

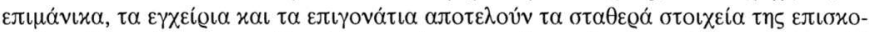

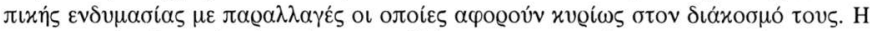

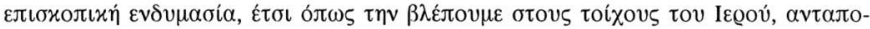

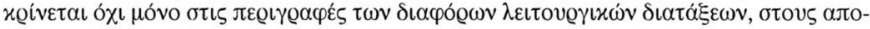

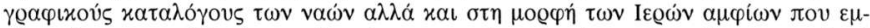

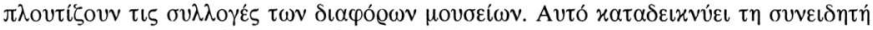

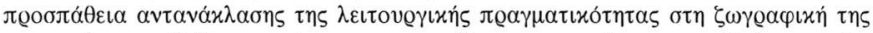

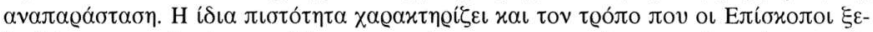

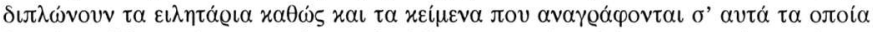

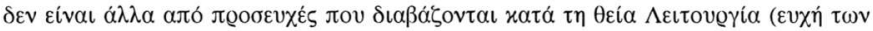

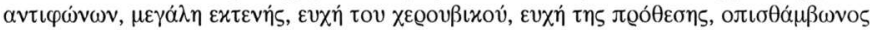

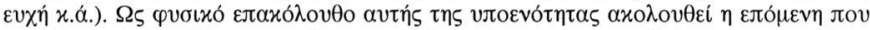

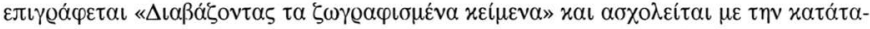

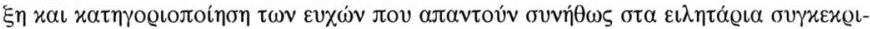

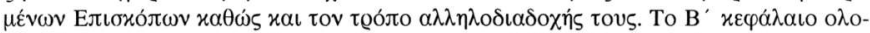

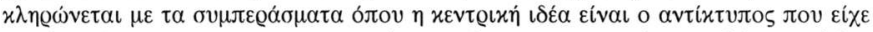

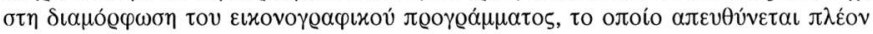

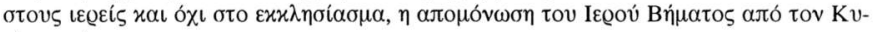
Qíwక vaó.

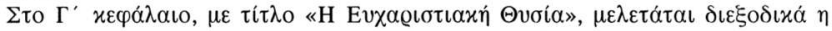

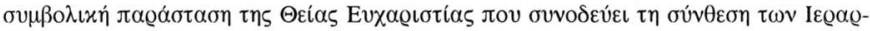

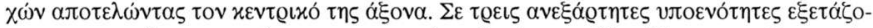

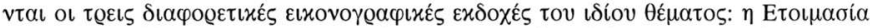

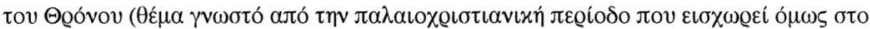

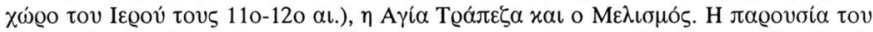

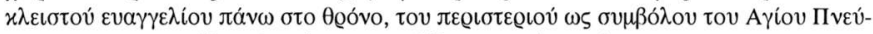

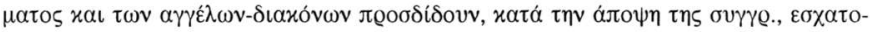

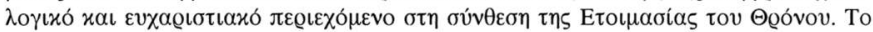

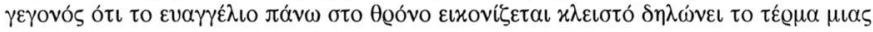




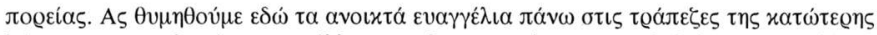

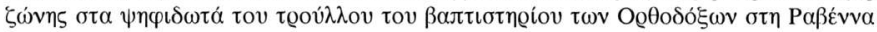

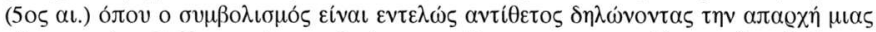

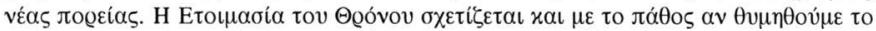

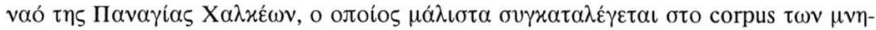

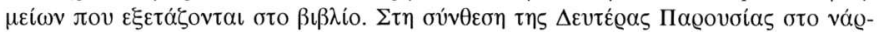

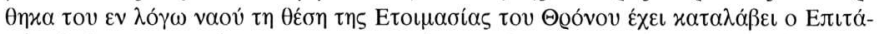

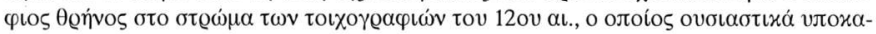

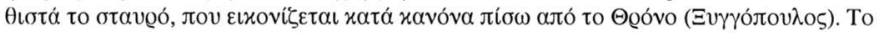

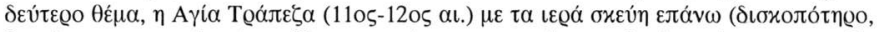

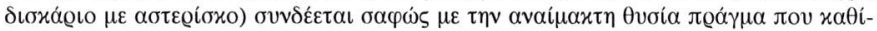

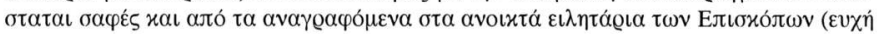

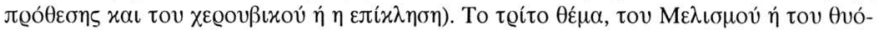

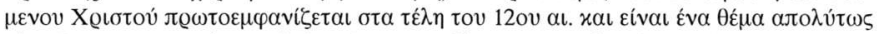

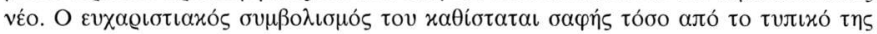

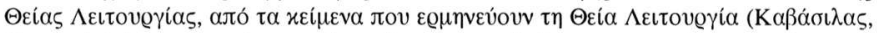

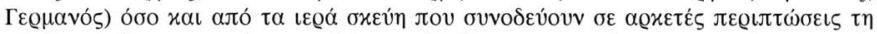

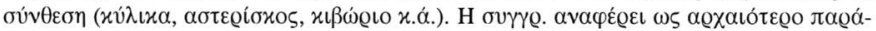

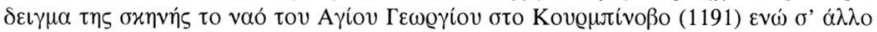

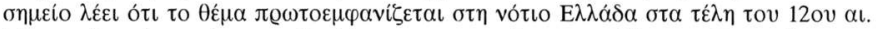

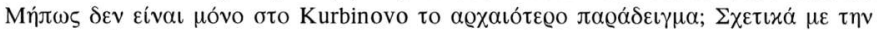

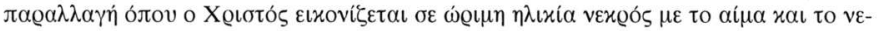

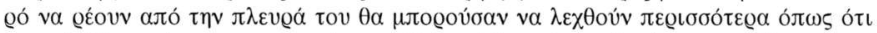

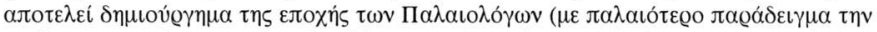

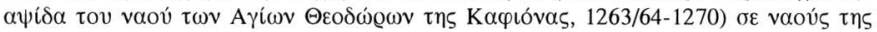

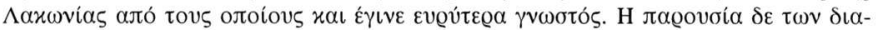

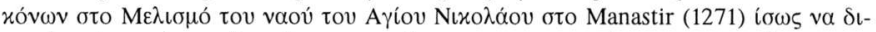
xaı

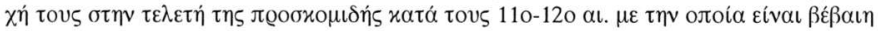

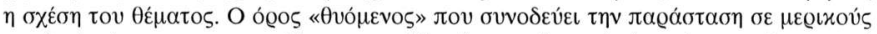

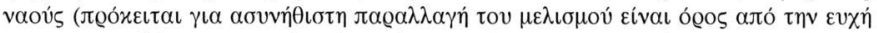

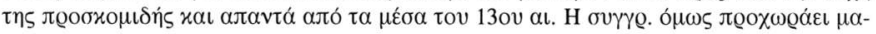

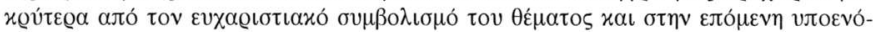

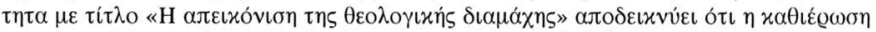

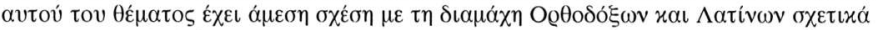

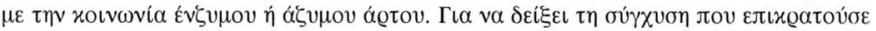

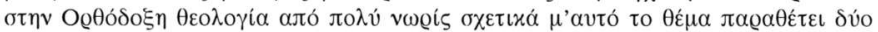

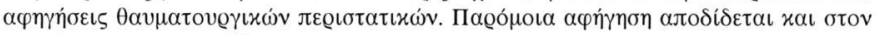

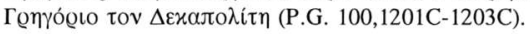

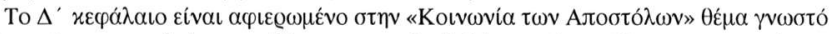

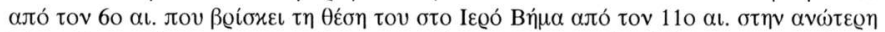

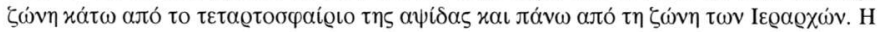

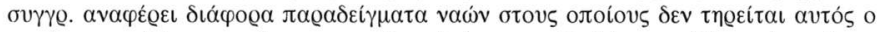

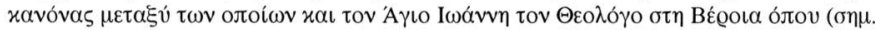

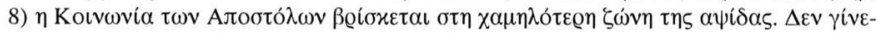

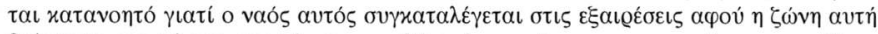

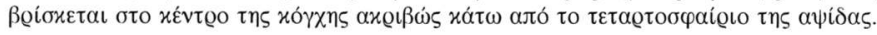




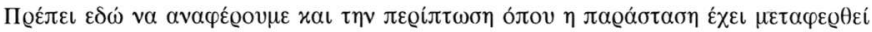

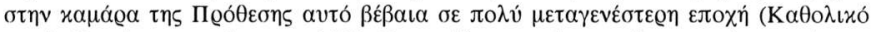


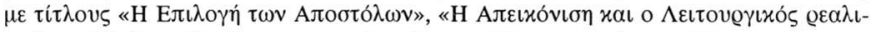

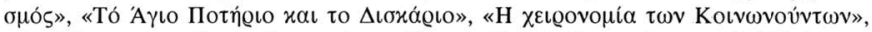

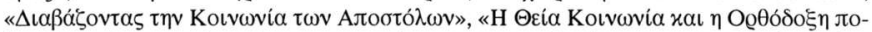

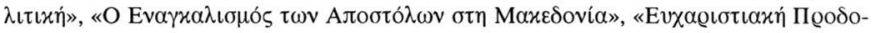

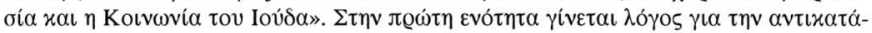

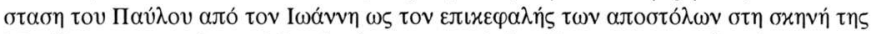

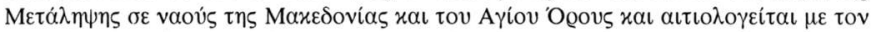

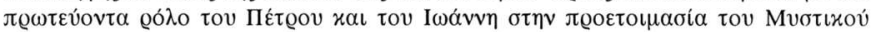

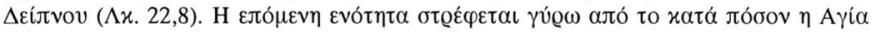

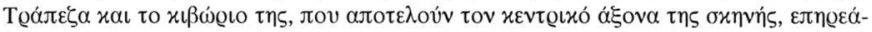

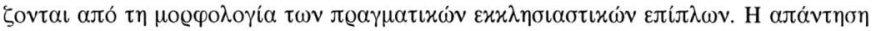

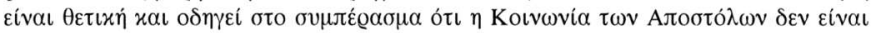

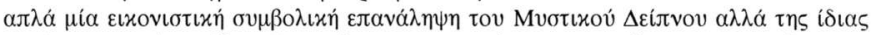

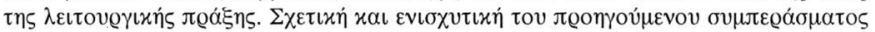

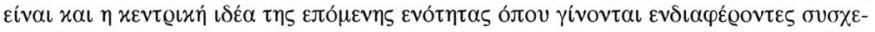

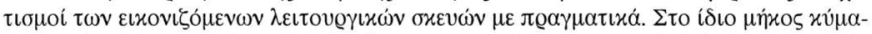

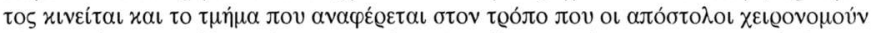

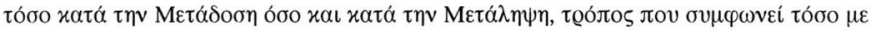

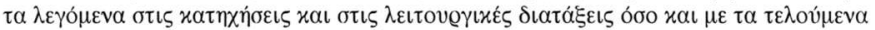

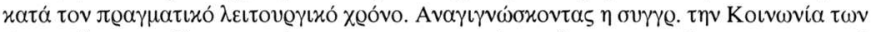

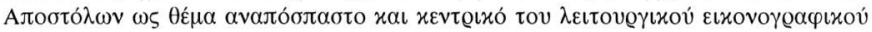

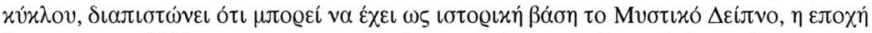

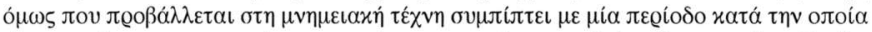

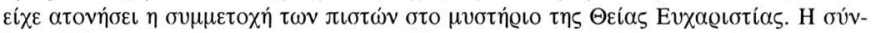

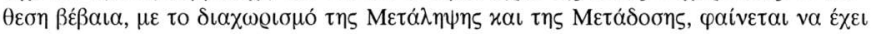

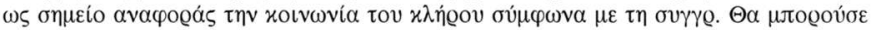

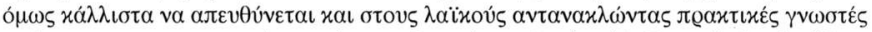

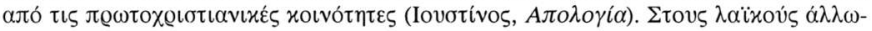

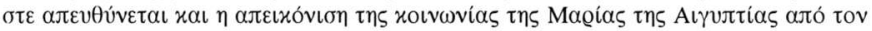

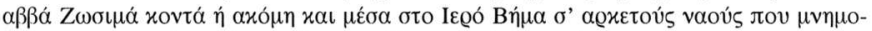

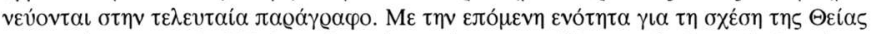

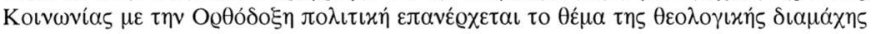

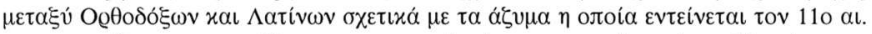

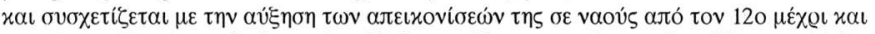

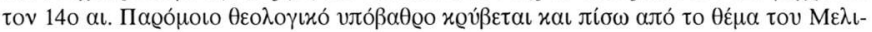

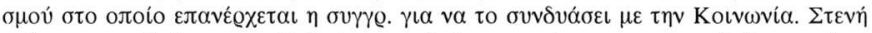

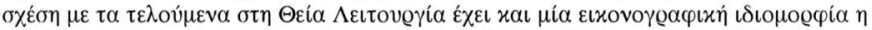

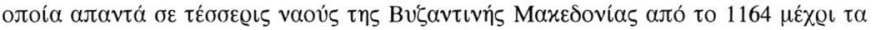

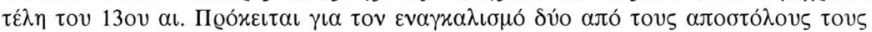

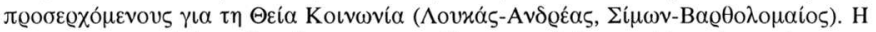

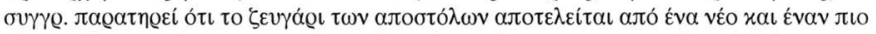

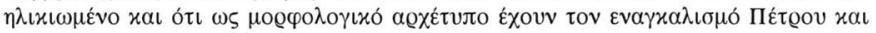

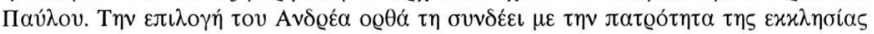

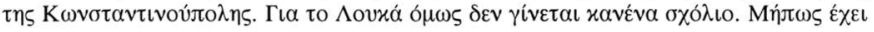




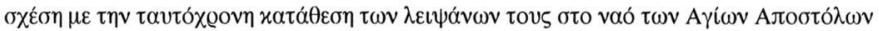

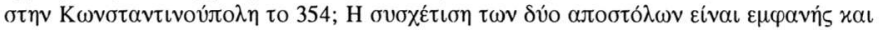

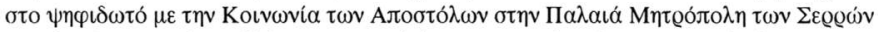

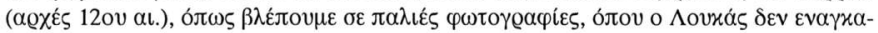

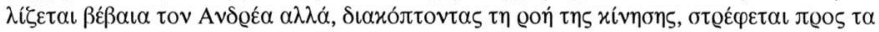

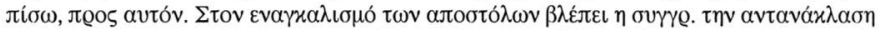

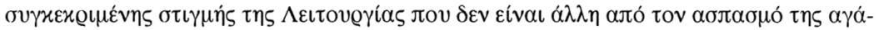

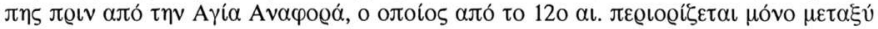

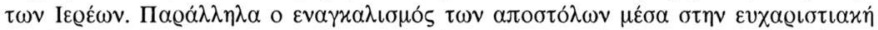

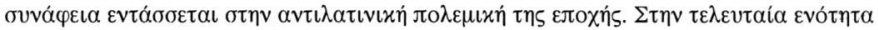

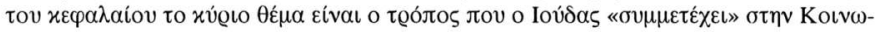

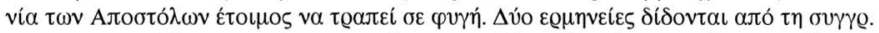

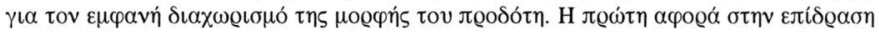

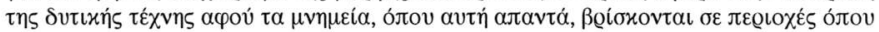

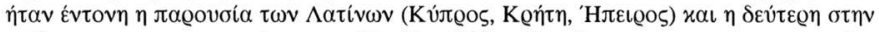

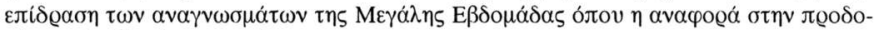

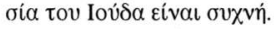

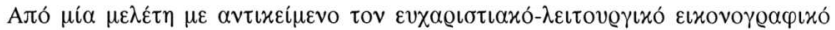

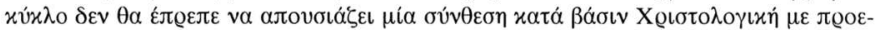

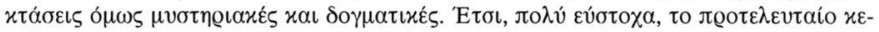

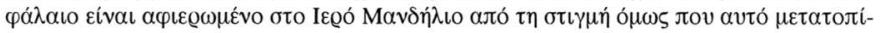

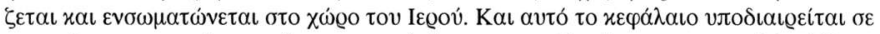

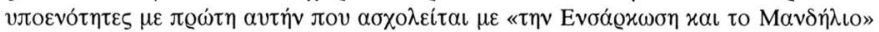

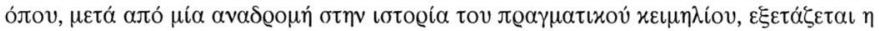

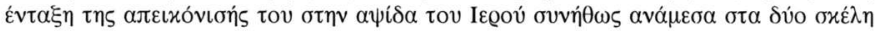

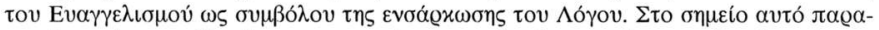

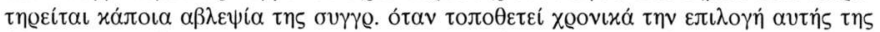

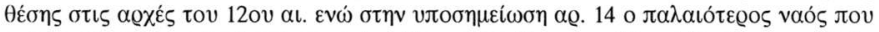

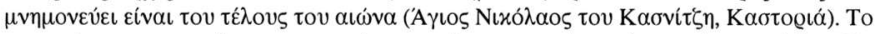

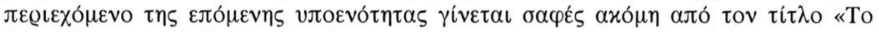

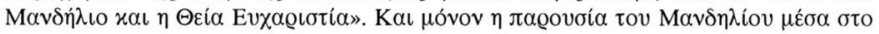

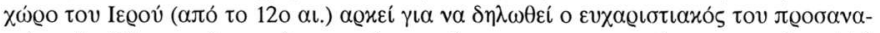

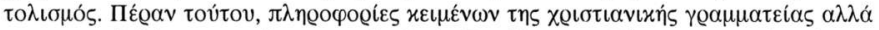

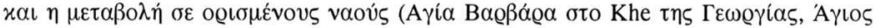

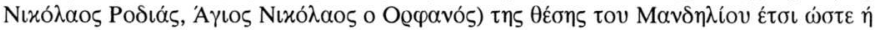

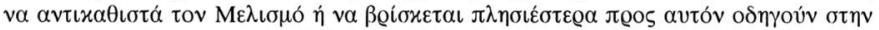

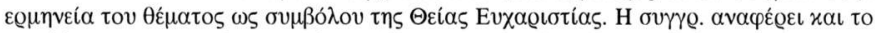

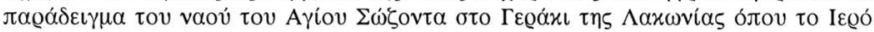

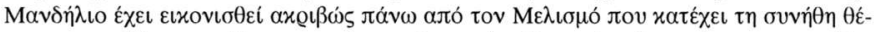

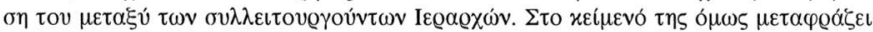

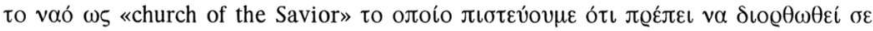

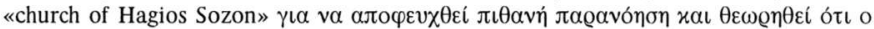

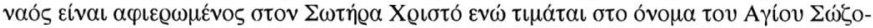

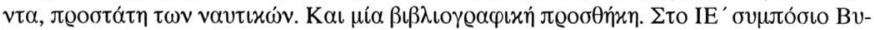

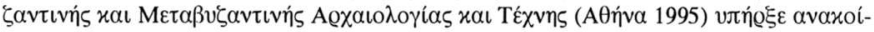

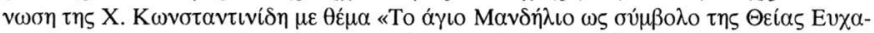

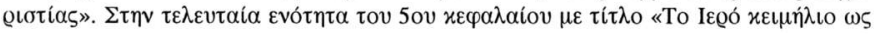




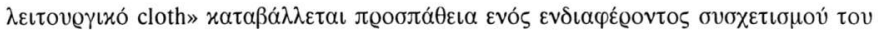

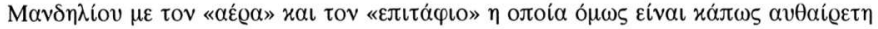

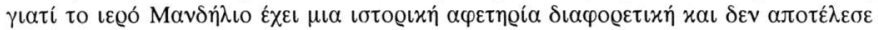

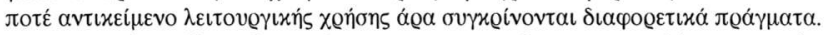

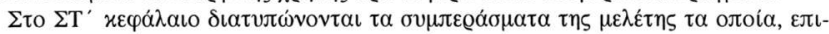

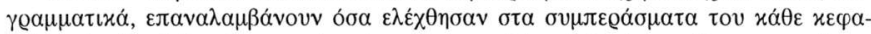

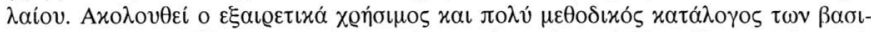

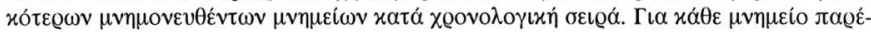

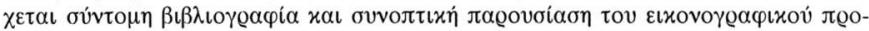

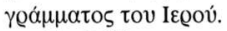

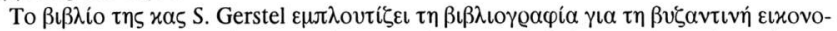

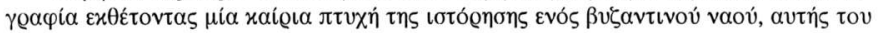

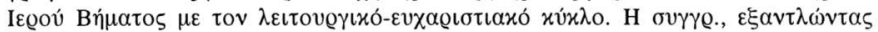

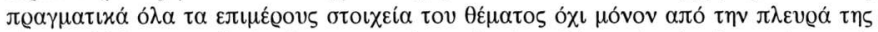

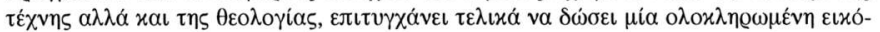

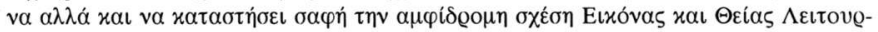

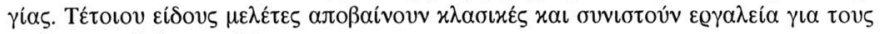

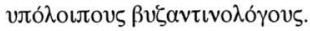

